\title{
The living arrangements of older adults in sub-Saharan Africa in a time of HIV/AIDS
}

\author{
Zachary Zimmer \\ Population Council \\ Julia Dayton \\ Population Council
}

Follow this and additional works at: https://knowledgecommons.popcouncil.org/departments_sbsr-pgy

Part of the Demography, Population, and Ecology Commons, Family, Life Course, and Society Commons, and the International Public Health Commons How does access to this work benefit you? Let us know!

\section{Recommended Citation}

Zimmer, Zachary and Julia Dayton. 2003. "The living arrangements of older adults in sub-Saharan Africa in a time of HIV/AIDS," Policy Research Division Working Paper no. 169. New York: Population Council. 
The Living Arrangements of Older Adults in sub-Saharan Africa in a Time of HIV/AIDS

Zachary Zimmer

Julia Dayton

$\varangle$

[I]

2003 No. 169

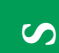

[I]

\&

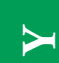

u

$\mapsto$

$\mapsto$

0

$\theta$

1 Population Council 


\title{
The Living Arrangements of Older Adults in sub-Saharan Africa in a Time of HIV/AIDS
}

\author{
Zachary Zimmer \\ Julia Dayton
}

Zachary Zimmer and Julia Dayton are Research Associates, Population Council, New York. 


\begin{abstract}
The detrimental consequences of the AIDS epidemic for older adults in subSaharan Africa suggest the need to investigate their characteristics, living situations, and well-being. In this study, we examine the living arrangements of persons aged 60 and older in 16 countries. Data come from the household roster component of recent Demographic and Health Surveys. The focus is on the tendency of the elderly to live with children and grandchildren, and we examine distributions and determinants. Results show that older adults in sub-Saharan Africa live in a variety of household arrangements. Men are more likely to be living in a nuclear household, while women are more likely to be living in extended families. Regressions show that determinants of living with children and grandchildren differ by sex. Taking advantage of survey items on the survival and whereabouts of parents of children, we also examine whether older adults living with grandchildren are involved in fostering or orphaning situations. Those living in countries characterized by high levels of AIDSrelated mortality are more likely to be living with grandchildren, with grandchildren but no children in the household, and with orphaned grandchildren. The percent living with one or more double-orphaned grandchildren is strongly associated with AIDS-related mortality, suggesting that the epidemic may be having adverse influences on the living situations of older adults. Knowing about the types of households in which older people live is a first step to understanding their needs in a part of the world with limited resources.
\end{abstract}

This material may not be reproduced without written permission from the authors. For a list of Policy Research Division Working Papers, including those available for downloading in PDF format, see www.popcouncil.org/publications/wp/prd/rdwplist.html. 
Research on population aging in some developing regions is advancing theoretically, and the volume of studies is expanding; yet older adults in sub-Saharan Africa have been largely neglected in this effort. Much of the increased attention in other regions is motivated by projections showing that populations are changing from a younger to an older age structure, the result primarily of rapid and recent declines in fertility. East Asia, Southeast Asia, and Latin America are prime examples. Hence, demographers and other social scientists have begun to deliberate upon the consequences of this trend for the societies in which older adults live (Martin and Kinsella 1994). Key topics include the living situations of older adults, the changes in population health, and the prospect of social support for older adults. The current paper addresses the first of these topics directly for Africa and touches indirectly on the other two topics.

Although Africa's age structure is not primed for radical transformation in the near future, the region's population is aging at a significant pace. The current population of about 30 million people aged 60 and older living in sub-Saharan Africa is expected to double by 2025 , while the proportion 60 and older is expected to rise from the current 4.8 percent to over 7 percent by 2050 (United Nations 2001). These increases are modest compared to those expected in East Asia, but will be more rapid in places now experiencing fertility decline. In Kenya, for instance, fertility rates have dropped from over eight births per woman to about four in just 30 years, and the decline is expected to continue. There are only a little over 1 million adults aged 60 and older living in Kenya today, but this total is expected to increase fourfold to 4.5 million by 2040 . Other countries experiencing or expected to experience rapid fertility decline and subsequent aging of their populations over the next several decades include Ghana, Nigeria, and Zimbabwe.

There is also growing concern that older people across Africa are being adversely affected by the AIDS epidemic (Barnett and Blaikie 1992; Hunter and Williamson 1998; National Research Council 1996; World Bank 2000). Although unlikely to be infected themselves, older adults are a key group of survivors who are especially affected if an offspring suffers or dies from HIV/AIDS. When an offspring contracts HIV/AIDS, the older adult may become the caregiver of the infected child, and later the caregiver to orphaned grandchildren - circumstances that can create financial, health, and psychological burdens. According to Albert and Cattell (1994), living arrangements of older 
adults in developing societies reflect lifetime strategies aimed at securing housing, material goods, and other items necessary to ensure physical and emotional well-being. An unwanted consequence of HIV/AIDS could be that at the time in life when older adults expect support from their family, they end up having to provide support to others instead and possibly have to sacrifice their own well-being.

Although these concerns are well-founded, there has been limited quantitative evidence of these effects in Africa. A team of researchers, led by John Knodel, has been in the forefront of documenting the effects of AIDS on older persons living in Thailand. They have found that two-thirds of adults with AIDS coresided with or lived next to their parents and that a parent or older-generation relative cared for 70 percent of adults who eventually died from AIDS (Knodel, VanLandingham, Saengtienchai, and Im-em 2001). They also documented financial burdens on the elderly as a result of caring for their sick children (Knodel, Saengthienchai, Im-em, and VanLandingham 2001). Similar patterns were found in smaller studies from Africa. One study in Uganda and another in Zimbabwe found that terminally ill AIDS patients were often cared for by their parents and that this care can cause financial burdens, mostly associated with care of an ill adult and care of orphans (Ntozi and Nakayiwa 1999; World Health Organization 2002). The above-mentioned studies used generally purposeful and nonprobability sampling techniques and do not inform us about the living arrangements and well-being of the elderly in the population at large.

We know of two studies from sub-Saharan Africa that use population-based samples, neither of which showed the expected large negative effects of HIV/AIDS on the well-being of the elderly. A quantitative study from rural Tanzania assessed the impact of prime-age adult mortality on the body mass index (BMI) of people over age 50 (Ainsworth and Dayton 2003). The authors found some effects on BMI, but BMI recovered over time, suggesting that the effects of the epidemic on the health of older adults may not be as severe as predicted. ${ }^{1}$ The only study we know of that analyzed the effects of the AIDS epidemic on living arrangements used data from the Demographic and Health Survey in South Africa and found few if any effects over time of rising HIV/ AIDS rates on living arrangements (Merli and Palloni 2001). No studies have made comparisons across countries with varying levels of AIDS infection. 
The current study examines the living arrangements of older adults in East and West Africa, with specific reference to living with children and grandchildren. The analyses are meant to serve two main purposes. First, given a paucity of literature on older adults in sub-Saharan Africa, we provide some basic descriptive information on the types of households in which older adults in the region live. Rather than providing data from individual countries, our aim is to offer a broad view of the region as a whole. Second, we examine how these arrangements are associated with indicators of the HIV/ AIDS epidemic, again maintaining a regional framework.

\section{LiVing ARRAngements OF OLDER Adults}

\section{Living arrangements in developing countries}

Throughout the developing world, the family is the key institution for older adults, and their living arrangements are a fundamental determinant of their well-being (Albert and Cattell 1994; Cowgill 1986; Knodel and Debavalya 1997). The aged, much like the young, tend to require support for instrumental (i.e., functional) tasks such as cooking and shopping, as well as material and psychological support to ensure their survival, particularly when they no longer work for pay and begin to suffer from ailments that limit their dexterity and ability to carry out tasks necessary for daily survival. While not every older adult experiences a substantial decline in ability to function, the longer an individual lives, the greater is the chance he or she will require support. While support comes from a combination of public and private sources in developed countries, the family tends to be the cornerstone of social support in the developing world. This is particularly the case in places, such as sub-Saharan Africa, with weak institutional security mechanisms.

Much research on living arrangements has concentrated on individual-level determinants, which are important for explaining differences across groups and for forecasting future needs. A "modernization" perspective (Goode 1963; Levy 1966) is frequently employed as a framework for hypotheses regarding individual determinants of living arrangements (e.g., Aykan and Wolf 2000; Bongaarts and Zimmer 2002; Martin 1989; DeVos 1990). This approach assumes that living with adult children and grand- 
children would be more common in traditional agricultural societies and would become less common as development, industrialization, and division of labor occur. The reasons for smaller and less intricate household formations include changes in work, which becomes more dependent upon individual skill level rather than on the fortunes of the family; changes in employment opportunities, which occur with greater regularity in urban rather than rural areas; and changes in attitudes, the desire for independent living, and the subsequent movement to public instead of private support systems. Declines in fertility, also characteristic of a modernizing society, lead to smaller family sizes, creating another means through which households become smaller and less complex. As societies modernize, the knowledge that older adults possess and the resources that they have accumulated throughout life become less important for success of the younger generation. This decreases the older generation's ability to demand support from younger members of their family. Although countries in sub-Saharan Africa may be too similar to one another with respect to socioeconomic development to allow us to test for modernization's impact on a macro level, on an individual level one would expect elderly populations with more education and those living in urban areas to be more likely to live independently of children and grandchildren (DeVos 1990; Martin 1989).

While coresidence with children is common for older adults in the developing world and living alone is rare (Albert and Cattell 1994), rapid reductions in coresidence between older adults and their adult children are occurring in Japan and South Korea, supporting the modernization perspective (Knodel and Debavalya 1997). On the other hand, rapid socioeconomic development in much of Asia, for example in Taiwan, China, Thailand, and Singapore, has not led to major changes in coresidence patterns (Asis et al. 1995; Hermalin 1995). Bongaarts and Zimmer (2002), in their examination of 43 countries in Africa, Latin America, and Asia, found coresidence with an adult child to be least common in Africa and most common in Asia; within Africa coresidence was less common in sub-Saharan countries than in North Africa. This pattern occurs despite the fact that sub-Saharan Africa is the poorest region in the world. It is also uncertain whether rates of coresidence were ever very high in developed countries prior to industrialization, casting some doubt on the premises from which modernization theory is built (Nydegger 1983). Bongaarts and Zimmer also found that adults more often tended to 
live with children in countries where educational attainment is lower, supporting the modernization idea. But other measures of socioeconomic development, such as GNP per capita, had little impact, suggesting that while there is something about education that influences living arrangements on a macro level, modernization indicators otherwise do not hold up.

When it comes to individual determinants of living arrangements, studies have mostly focused on East and Southeast Asia, where reductions in family size are reducing the availability of kin (Andrews et al. 1986; Anh et al. 1997; Cameron 2000; Casterline et al. 1991; Chan 1997; DaVanzo and Chan 1994; Knodel and Chayovan 1997; Logan, Bian, and Bian 1998; Martin 1989; Natividad and Cruz 1997; Rajan, Mishra, and Sarma 1995; Zimmer and Kim 2001). Several studies of this nature have also been conducted in Latin America (DeVos 1998, 1990; Palloni, DeVos, and Palaez 1999). Higher education has consistently been found to be associated with lower rates of coresidence (DaVanzo and Chan 1994), although living in urban rather than rural areas has been shown, fairly consistently, to be associated with coresidence with children (Andrews et al. 1986; Zimmer and Kim 2001). With respect to other individuallevel determinants, Martin (1989) found that being married decreased the likelihood of coresidence with a child in Asia, while DeVos (1990) showed that it increased the chances for living in extended families in Latin America. As for gender, there may be an interaction with being unmarried. Unmarried women and married men are more likely to coreside with children than are married women and unmarried men (DeVos 1990; Logan, Bian, and Bian 1998). Age has been found to be negatively or not significantly associated with coresidence (DeVos 1990; Martin 1989)

\section{Living arrangements in sub-Saharan Africa}

Studies of living arrangements in sub-Saharan Africa are mostly concentrated in anthropological and ethnographic fields, and tend to be limited to one ethnic group living in a particular geographic area (Albert and Cattell 1994; Apt 1992; Cattell 1990; Hoddinott 1993; Peil 1985; Thomas 1995). Two studies examine evidence for an entire country (Adamchak et al. 1991; Apt 1992), and none includes comparisons between countries. Under these circumstances it is difficult to draw conclusions about national or 
regional patterns or to compare levels and determinants of living arrangements in Africa with other regions of the world. Among the characteristics that can be gleaned from this past work, older women are commonly described as living as dependents in multigenerational households headed by a son. Yet, widows can be heads of households. Older men are commonly described as being household heads living with children and one or more wives. A small proportion of older adults - usually less than 5 percent-are described as living alone.

Research from elsewhere in the developing world tends to emphasize the importance of coresidence between an older adult and an adult child. It is through this arrangement that transfers of material and other resources take place across generations (Palloni 2000). Although coresidence with an adult child is no doubt critical for support of older adults in sub-Saharan Africa, living with grandchildren is also likely to be an important living arrangement. Unlike the tradition in Western families, where parents in nuclear families raise their children, the tradition in Africa is to live with extended families. We found no reports specifying the share of older adults living with grandchildren, although living in three-generation households is thought to be quite common (Albert and Cattell 1994). In addition, child fostering - that is, sending one or more children to live with

someone other than the parents - is a practice common in Africa, particularly in West Africa. Many African children spend substantial portions of their childhood away from their parents (Lloyd and Desai 1992). In many African societies, grandparents are the most common recipients of foster children.

\section{Possible effects of the AIDS epidemic on living arrangements}

It is widely believed that the AIDS epidemic has the potential to alter living arrangements and, in turn, the support mechanisms of older adults (VanLandingham, Knodel, Im-em, and Saengtienchai 2000). Yet it is difficult to predict the extent of such alterations, since a health event of this magnitude has rarely been experienced. Merli and Palloni (2001) equate the epidemic with the European Black Plague and suggest that the changes in household arrangements that will take place in Africa may be of a similar scope. Adults in their prime years (ages 15 to 50) are most likely to contract HIV/AIDS; and because AIDS is fatal, victims often leave behind dependent children 
and older parents who require support. Recent estimates for ten African countries find orphan rates exceeding 9 percent in Kenya, Tanzania, Malawi, and Mozambique and in excess of 12 percent in Uganda, Zambia, and Zimbabwe (Case, Paxson, and Ableidinger 2002). High and increasing rates of orphanage could be leading to changes in family living arrangements and in particular contributing to the emergence of many households that consist of only the older grandparent generation (aged over 60) and the generation under 15, with no members of the so-called middle generation. Such a situation would clearly strain older adults through its influence on financial, health, and psychological well-being. Yet, in verifying this situation in the case of Africa, it is necessary to keep in mind that fostering-in by grandparents is already quite common even without the influence of AIDS.

Although researchers have studied many dimensions of how children are being affected by the epidemic, including their living arrangements (e.g., Bicego, Rutstein, and Johnson 2001; Case, Paxson, and Ableidinger 2002; World Bank 1999), very little analysis has been done from the perspective of the older generation. On the basis of the preceding discussion, we suggest at least three ways in which AIDS could change the living situation of older adults. First, it could reduce the supply of adult children with whom to live, thus reducing the tendency to coreside with such children. Second, it might increase the supply of grandchildren who require support, thereby increasing the tendency of the elderly to coreside with grandchildren. Third, for those who live with grandchildren, the epidemic could change the balance from coresidence as a fostering arrangement to coresidence as a response to the death of the grandchildren's parents. These types of changes clearly place added pressures on older adults with respect both to their own support and to the support they can provide for other family members.

\section{Hypotheses}

In light of the theory and the empirical evidence described above, we can formulate a number of expectations. First, we anticipate the prevalence of coresidence with children and grandchildren to be high in Africa, while we expect the incidence of living alone to be low. We hypothesize that age can have varying effects. Age will be positively associated with increased care needs, which can lead to a greater chance of coresidence 
with caretaking family members. But higher age also means that children of older adults are more likely to be married and to be living independently, thus decreasing the chances of coresidence. Because these children have children of their own, there may be a greater opportunity of living in three-generational families. We will examine and weigh these varying effects in our analysis. On the basis of research from elsewhere and of the tenets of modernization theory, we expect the elderly with more formal education and those living in urban areas to be less likely to live with children and grandchildren, as they are likely to have more control over resources and thus capable of greater independence. We also anticipate associations between the extent of the AIDS epidemic within a given country and certain living arrangements. We expect that older adults living in countries with higher rates of AIDS deaths are less likely to live with their adult children but more likely to live with their grandchildren.

\section{USING THE DHS TO STUDY OLDER ADULTS IN \\ SUb-SAHARAN AFRICA}

In his presidential address to the Population Association of America, Albert Hermalin cited the underused potential of representative-sample fertility surveys, which in the course of data collection document information on household members, for exploring living arrangement of older adults (Hermalin 1993). In the current study, we employ data from the household component of 16 Demographic and Health Surveys (DHS) conducted in East and West sub-Saharan Africa between 1995 and 2000. Although such data have been used in the past to examine living arrangements among family members (e.g., Aykan and Wolf 2000; Bongaarts and Zimmer 2002), such analyses are still infrequent.

In general, DHS studies involve nationally representative samples, although in very few instances parts of countries may be omitted owing to practical considerations. This normally eliminates no more than a small percentage of a country's population (Ayad, Barrere, and Otto 1997). The main objective of the DHS is to collect information on the reproductive and health behavior of women aged 15-49. In order to identify these women, each DHS includes a household component that records, for each member living in the household, age, sex, relationship to head, education level, and residential 
status, and, for children, the presence and survival status of their parents. To ascertain the specific living arrangements of older adults, it is necessary to reconstruct the relationships using relationships to the household head as the index. ${ }^{2}$ The DHS asks about who is in the household at the present time (de facto household residence) and who is in the household usually (de jure residence). We use the latter-usual residents-for our determination of household composition.

We begin by examining living arrangement distributions for persons 60 and older living in sub-Saharan Africa. Our primary concern here is whether an older adult lives with a child and/or a grandchild, relationships that are easily reconstructed from the DHS household roster. We then assess several determinants of living with children and grandchildren. By relying on the information provided by the DHS, we are limited in our determinants, which include the age of the older adult, his or her sex, marital status (proxied by living with a spouse), education, and whether the household is in a rural or urban area. For household members under age 15, most surveys ask about the survival status and living situation of the parents, that is, whether they are alive or dead and, if alive, whether they live in the household with their children or live elsewhere. This information provides the additional ability to categorize older adults who live with grandchildren as living with grandchildren who live with their own parents and, if without, whether this is due to a parent's death or due to the parent's being absent for other reasons. Where levels of HIV/AIDS are high, we would expect that living with a grandchild whose parents have died is more common and that, where this is more common, the reason could well be a high number of AIDS-related deaths. Therefore, using data from UNAIDS (1997), we categorize countries according to their AIDS death rate, that is, the number of deaths per 1,000 population in 1997 where the cause of death was AIDS-related, and we examine living arrangements across these categories. ${ }^{3}$ We use death rates rather than prevalence rates since it is actual deaths that are most likely to influence the living arrangements of older adults.

Among the variables that would also be useful but are not available from the DHS are the number and proximity of children living outside the household, marital status of all family members (recorded in some but not all surveys), age and birth order of all living children, employment information, and other socio-demographic character- 
istics of household members. These limitations confine our analyses to certain specific living arrangements and basic demographic determinants.

Table 1 lists the countries in our study, selected characteristics of the countries, and the DHS sample from each. In the table we divide countries into eight each from East and West sub-Saharan Africa, according to the definitions provided by the United Nations. The combined population of these 16 countries, about 381 million, represents 79 percent of the total population of East and West sub-Saharan Africa. These numbers highlight a main advantage of the DHS, namely, the breadth of coverage across subSaharan Africa, allowing for generalization and for the determination of regional trends. For most of our analysis, we pool the data from the 16 countries and report regional results. In the text that follows, we refer to the region as sub-Saharan Africa, although

Table 1 Characteristics of countries and samples

\begin{tabular}{|c|c|c|c|c|c|c|c|}
\hline Country & $\begin{array}{c}\begin{array}{c}\text { Popu- } \\
\text { lation } \\
\text { (millions) }^{\mathrm{a}}\end{array} \\
\end{array}$ & $\begin{array}{c}\text { GNP } \\
\text { per } \\
\text { capita } \\
(\mathrm{US} \$)^{\mathrm{a}}\end{array}$ & $\begin{array}{c}\text { Crude } \\
\text { death } \\
\text { rate from } \\
\text { AIDS }^{\mathbf{b}}\end{array}$ & $\begin{array}{c}\text { Year of } \\
\text { last DHS } \\
\text { survey }\end{array}$ & $\begin{array}{l}\text { Number } \\
\text { aged } 60 \\
\text { and older } \\
\text { in DHS } \\
\text { survey }^{\mathrm{e}}\end{array}$ & $\begin{array}{c}\text { Percent } \\
\text { aged } 60 \\
\text { and older }^{\mathrm{e}}\end{array}$ & $\begin{array}{c}\text { Percent of } \\
\text { households } \\
\text { with someone } \\
\text { aged } 60 \\
\text { and older } \\
\end{array}$ \\
\hline Total & $381.3^{\mathrm{d}}$ & $270^{c}$ & $3.4^{\mathrm{c}}$ & 1995-2000 & 33,176 & 6.0 & 24.0 \\
\hline \multicolumn{8}{|l|}{ East Africa } \\
\hline Ethiopia & 59.7 & 110 & 4.2 & 2000 & 3,748 & 5.5 & 22.9 \\
\hline Kenya & 28.8 & 340 & 4.9 & 1998 & 2,039 & 5.7 & 20.2 \\
\hline Madagascar & 14.4 & 250 & 0.0 & 1997 & 1,850 & 5.3 & 21.2 \\
\hline Mozambique & 19.1 & 140 & 4.5 & 1997 & 2,458 & 5.8 & 22.1 \\
\hline Tanzania & 31.3 & 210 & 4.8 & 1999 & 1,166 & 6.4 & 26.9 \\
\hline Uganda & 22.8 & 330 & 7.7 & 1995 & 1,786 & 5.0 & 19.7 \\
\hline Zambia & 9.7 & 370 & 11.4 & 1996 & 1,754 & 4.5 & 20.1 \\
\hline Zimbabwe & 11.2 & 720 & 11.1 & 1999 & 1,685 & 6.3 & 21.5 \\
\hline \multicolumn{8}{|l|}{ West Africa } \\
\hline Benin & 6.2 & 380 & 0.7 & 1996 & 1,625 & 6.0 & 29.1 \\
\hline Burkina Faso & 11.6 & 250 & 3.8 & 1999 & 1,998 & 6.2 & 31.6 \\
\hline Ghana & 19.7 & 390 & 1.3 & 1998 & 1,486 & 6.9 & 21.8 \\
\hline Guinea & 7.5 & 550 & 0.9 & 1999 & 2,181 & 6.5 & 34.0 \\
\hline Mali & 11.0 & 260 & 0.7 & 1995 & 2,837 & 5.8 & 26.6 \\
\hline Niger & 10.0 & 200 & 0.6 & 1998 & 1,899 & 5.4 & 26.2 \\
\hline Nigeria & 113.8 & 280 & 1.3 & 1999 & 2,143 & 5.6 & 23.5 \\
\hline Togo & 4.5 & 340 & 4.6 & 1998 & 2,521 & 6.2 & 27.3 \\
\hline
\end{tabular}

Sources: a Population Reference Bureau (2000) World Population Data Sheet. Washington, DC: Population Reference Bureau. b Deaths from AIDS per 1,000 population, from UNAIDS (1997). c Weighted average across countries in the current study. dTotals for countries in the current study. e Most recent DHS survey. 
we acknowledge that our sample does not include countries from Central Africa or the country of South Africa.

It is difficult to divide these countries into meaningful categories of economic development. The GNP per capita (in US\$) in these countries is very low, ranging from $\$ 110$ in Ethiopia to $\$ 720$ in Zimbabwe. All but two of the countries have a GNP per capita below $\$ 400$. Given a relative lack of variation in levels of economic development, we do not test theories of modernization in the current study. AIDS-related mortality rates, on the other hand, vary considerably, allowing us to examine living arrangements across countries with different levels of HIV/AIDS. AIDS-related mortality is higher in East Africa. In 1997 there were more than 11 deaths per 1,000 population due to AIDS in Zambia and Zimbabwe and more than 7 in Uganda, rates that exert an influence on adult mortality. There was less than 1 death per 1,000 in Benin, Guinea, Madagascar, Mali, and Niger.

We define older adults as persons 60 and older. According to the sample characteristics reported in Table 1, the average number of persons in the DHS sample aged 60 and older per country is about 2,000, and the total sample size exceeds 33,000. Although older adults make up only about 6 percent of the total population within the region, older adults are found frequently within individual households. About one in four households across the region contains an older adult, and this fraction is as high as 34 percent in Guinea and not lower than about 20 percent in any country. Since most of our analysis is conducted on a pooled sample of the 33,000 cases, data within countries are weighted to be nationally representative. Our study, for the most part, considers regional trends, and the pooled data are weighted so that the results are regionally representative. ${ }^{4}$

Table 2 presents selected characteristics of older people living in each country. The percent female among the elderly ranges from 59 percent in Togo to 46 percent in Mali and reflects differences in sex-specific mortality within countries. Men are much more likely to be living with a spouse, in part because of old-age mortality that favors women, the fact that men often marry younger women, and the tradition of polygamy in some cultures. Another stark difference between the sexes is the percent with schooling, which favors men at a greater than 2 to 1 ratio across the region. Levels of schooling are generally higher in East as compared with West Africa. 
Table 2 Selected characteristics of older adults in the DHS surveys

\begin{tabular}{|c|c|c|c|c|c|}
\hline Country & $\begin{array}{l}\text { Percent } \\
\text { female }\end{array}$ & $\begin{array}{c}\text { Percent } \\
\text { of men } \\
\text { living with } \\
\text { spouse }\end{array}$ & $\begin{array}{c}\text { Percent } \\
\text { of women } \\
\text { living with } \\
\text { spouse }\end{array}$ & $\begin{array}{c}\text { Percent } \\
\text { of men } \\
\text { with some } \\
\text { schooling }\end{array}$ & $\begin{array}{c}\text { Percent } \\
\text { of women } \\
\text { with some } \\
\text { schooling }\end{array}$ \\
\hline Total $^{\mathrm{a}}$ & 49.8 & 84.8 & 44.1 & 37.9 & 16.1 \\
\hline \multicolumn{6}{|l|}{ East Africa } \\
\hline Ethiopia & 48.1 & 90.3 & 39.3 & 9.8 & 1.2 \\
\hline Kenya & 53.9 & 80.1 & 43.3 & 63.6 & 29.8 \\
\hline Madagascar & 52.2 & 82.2 & 45.6 & 64.3 & 44.8 \\
\hline Mozambique & 51.2 & 82.3 & 43.8 & 49.3 & 14.4 \\
\hline Tanzania & 50.5 & 80.9 & 38.5 & 52.2 & 18.2 \\
\hline Uganda & 52.8 & 74.3 & 38.2 & 59.5 & 21.9 \\
\hline Zambia & 51.1 & 85.9 & 46.0 & 71.9 & 35.4 \\
\hline Zimbabwe & 53.4 & 73.1 & 40.6 & 75.4 & 56.6 \\
\hline \multicolumn{6}{|l|}{ West Africa } \\
\hline Benin & 52.7 & 78.9 & 43.1 & 21.9 & 8.3 \\
\hline Burkina Faso & 50.8 & 91.5 & 63.7 & 4.2 & 1.2 \\
\hline Ghana & 55.5 & 67.5 & 27.9 & 52.7 & 21.9 \\
\hline Guinea & 49.1 & 88.8 & 55.0 & 11.4 & 4.8 \\
\hline Mali & 46.3 & 93.1 & 60.9 & 9.2 & 3.6 \\
\hline Niger & 48.7 & 93.5 & 53.5 & 4.6 & 2.6 \\
\hline Nigeria & 46.9 & 86.9 & 47.6 & 46.6 & 27.0 \\
\hline Togo & 58.9 & 76.1 & 40.4 & 33.4 & 8.3 \\
\hline
\end{tabular}

a Weighted average across countries in the current study.

\section{RESULTS}

\section{Living arrangement levels and their determinants}

Table 3 shows one of the most basic divisions of households in which older adults in sub-Saharan Africa live, namely nuclear versus extended arrangements. Nuclear households are subdivided into four types (elderly persons living alone, with spouse only, with children only, or with spouse and children), and extended into two types (with grandchildren and/or children-in-law, or what can be called extended nuclear, and living with others). Older adults are fairly evenly split between those living in nuclear households and those living in extended households. Within nuclear households, living with a spouse and one or more children is most common. About 9 percent of older adults live alone, a figure much higher than the 3 to 5 percent reported by Albert and Cattell (1994).

There is great variation in these living arrangements by sex. Women are much more likely than men to live in extended households (almost 70 percent of women ver- 
Table 3 Percent of older adults in sub-Saharan Africa in specific nuclear and extended living arrangements

\begin{tabular}{lcrr}
\hline Living arrangement & Total both sexes & Men & Women \\
\hline Nuclear families & & & \\
Lives alone & 8.5 & 5.5 & 12.0 \\
With spouse only & 8.8 & 10.9 & 6.5 \\
With children only & 4.4 & 2.9 & 6.2 \\
With spouse and children & 23.5 & 37.6 & 7.1 \\
Extended households & & & \\
Extended nuclear (living with grandchildren & & & \\
$\quad$ and/or children in-law) & 31.7 & 24.7 & 39.8 \\
Living with others & 23.0 & 18.4 & 28.3 \\
Total & 100.0 & 100.0 & 100.0 \\
\hline
\end{tabular}

Note: Women significantly different from men at $\mathrm{p}<.05$ in all cases.

sus about 43 percent of men). On the other hand, 38 percent of men live in a nuclear family with a spouse and one or more children, compared with about 7 percent of women. One reason for this variation by sex is that women tend to live longer than men and may therefore have more grandchildren and in-law children with whom to live. Another possibility is that when the husband dies, a woman may need to move in with extended family for support. Indeed, we will see later in our regression analyses that living with a spouse substantially reduces the tendency of women to live with grandchildren. Finally, grandmothers, rather than grandfathers, may be seen as the more natural choice of individuals to assist in caring for grandchildren. At the same time, we see that 12 percent of older women in sub-Saharan Africa live alone, a proportion twice that of men.

Table 4 looks more closely at the proportions living with children and grandchildren. In total, 61 percent of older adults in our sample live with a child, and 52 percent live with an adult child (that is, a child 15 years of age or older). In addition, 43 percent live with a grandchild, confirming that in Africa living with one's grandchildren is almost as common as living with one's children. Furthermore, 13 percent of older adults live with at least one grandchild but without adult children, a situation that might be thought of as fostering-in. About 28 percent live in three-generation households, that is, with adult children and grandchildren.

We can make some assessment of the sex preference of the child with whom older adults live by examining whether older adults live with sons-in-law or daughters-in-law. 
Table 4 Percent of older adults in specific living arrangements involving children and grandchildren

\begin{tabular}{lccr}
\hline Living with & Total both sexes & Men & Women \\
\hline Children & 61.0 & 68.7 & 52.0 \\
Adult children & 52.3 & 54.6 & 49.6 \\
Grandchildren & 43.2 & 33.2 & 54.7 \\
Grandchildren under age 15 & 39.4 & 30.9 & 49.1 \\
Grandchild under 15 but no adult children & & & \\
$\quad$ in the household & 13.1 & 10.2 & 16.5 \\
Adult sons & 38.1 & 41.4 & 34.2 \\
Adult daughters & 25.1 & 28.3 & 21.4 \\
Children-in-law & 15.6 & 9.7 & 22.3 \\
Sons-in-law & 2.3 & 1.5 & 3.3 \\
Daughters-in-law & 13.5 & 8.5 & 19.4 \\
In three generations ${ }^{\mathrm{a}}$ & 27.7 & 22.2 & 34.1 \\
\hline
\end{tabular}

Note: Women significantly different from men at $\mathrm{p}<.05$ in all cases.

a Lives with a grandchild under 15 and an adult child.

First, living with a son-in-law suggests that the older adult lives with an adult female child, while living with a daughter-in-law suggests an adult male child is in the household. Second, where married children live provides an indication of preference since married children may set up an independent household elsewhere, but single children may be more inclined to remain with their parents. Given our data limitations, we cannot account for situations where there is an in-law child but the adult child either is living elsewhere or is deceased. Nonetheless, we have fairly good evidence that males are greatly preferred. The proportion living with a daughter-in-law is about six times greater than the proportion living with a son-in-law. In this sense, sub-Saharan Africa is similar to much of Asia, where patrilineal living arrangements prevail (Mason 1992). In patrilineal societies, males tend to control the primary resources and therefore can best financially support their elderly parents, while daughters-in-law care for their physical needs.

In addition, while men are more likely to be living with a child, women are more likely to be living with grandchildren, children-in-law, and in three-generation families. Indeed, it is more common to see elderly females living with a grandchild than with their adult child. Although there are sex differences in the percent of older adults in subSaharan Africa who live with children, the ratios of living with male versus female children, and with sons-in-law versus daughters-in-law, are fairly similar. The preference for living with sons exists for both elderly men and elderly women. 
In Table 5 we present logistic regression results showing the individual-level factors associated with three key living arrangements: living with an adult child, living with a grandchild under age 15, and living with a grandchild under 15 but with no adult child in the household. Given the statistically significant differences in the regression results by sex and the very different patterns of living with children versus living with grandchildren, we present results separately for men and women. This procedure also controls for country, which allows the results to be unbiased by the countries with larger populations. ${ }^{5}$ The coefficients are presented as log odds ratios. Each covariate is coded so that we expect a positive effect according to theoretical arguments presented earlier. For example, on the basis of the modernization perspective, we would expect the elderly living in rural areas and those with less education to be more likely to live with children and grandchildren.

Table 5 Logistic regression odds ratios for the determinants of specific living arrangements, considering men and women separately ${ }^{\mathrm{a}}$

\begin{tabular}{|c|c|c|c|c|c|c|}
\hline & \multicolumn{3}{|c|}{ Men } & \multicolumn{3}{|c|}{ Women } \\
\hline & $\begin{array}{l}\text { Living } \\
\text { with an } \\
\text { adult } \\
\text { child }\end{array}$ & $\begin{array}{l}\text { Living with } \\
\text { a grand- } \\
\text { child } \\
\text { under } 15\end{array}$ & $\begin{array}{l}\text { Living with } \\
\text { a grand- } \\
\text { child under } \\
15 \text { but no } \\
\text { adult child }\end{array}$ & $\begin{array}{l}\text { Living } \\
\text { with an } \\
\text { adult } \\
\text { child }\end{array}$ & $\begin{array}{l}\text { Living with } \\
\text { a grand- } \\
\text { child } \\
\text { under } 15\end{array}$ & $\begin{array}{l}\text { Living with } \\
\text { a grand- } \\
\text { child under } \\
15 \text { but no } \\
\text { adult child }\end{array}$ \\
\hline \multicolumn{7}{|l|}{$\overline{\text { Age }}$} \\
\hline 60 to 64 & 1.000 & 1.000 & 1.000 & 1.000 & 1.000 & 1.000 \\
\hline 65 to 69 & 0.982 & $1.266^{*}$ & $1.413 *$ & 0.928 & $0.807 *$ & 0.994 \\
\hline 70 to 74 & $0.782 *$ & $1.560 *$ & $2.004 *$ & 0.958 & $0.773 *$ & 0.945 \\
\hline 75 to 79 & $0.733 *$ & $1.317 *$ & $1.626^{*}$ & 0.938 & 0.987 & $0.791 *$ \\
\hline 80 and older & $0.699 *$ & $1.881^{*}$ & $2.312^{*}$ & 0.973 & 0.993 & $0.691 *$ \\
\hline \multicolumn{7}{|l|}{ Lives with spouse } \\
\hline No & 1.000 & 1.000 & 1.000 & 1.000 & 1.000 & 1.000 \\
\hline Yes & $2.104 *$ & $1.790^{*}$ & $2.986^{*}$ & $0.722 *$ & 0.962 & 1.081 \\
\hline \multicolumn{7}{|l|}{ Residence } \\
\hline Urban & 1.000 & 1.000 & 1.000 & 1.000 & 1.000 & 1.000 \\
\hline Rural & $0.784 *$ & 1.027 & $1.639 *$ & 1.313 & 0.951 & $1.489 *$ \\
\hline \multicolumn{7}{|l|}{$\begin{array}{r}\text { Has formal } \\
\text { education }\end{array}$} \\
\hline No & 1.000 & 1.000 & 1.000 & 1.000 & 1.000 & 1.000 \\
\hline Yes & $1.271 *$ & $1.096^{*}$ & 1.095 & 1.096 & 1.102 & $1.178^{*}$ \\
\hline LL & $-11,559.0$ & $-10,302.3$ & $-5,394.6$ & $-10,292.2$ & $-10,268.5$ & $-6,445.4$ \\
\hline $\begin{array}{l}\Delta-2 \mathrm{LL} \text { (all non- } \\
\text { country covariates) }\end{array}$ & 535.2 & $207.6^{*}$ & $340.5^{*}$ & $108.8^{*}$ & $58.9 *$ & $91.5 *$ \\
\hline
\end{tabular}


We look first at the results for men. They indicate that individual characteristics are significantly associated with all three types of living arrangements. As men age, they are less likely to live with an adult child but more likely to live with grandchildren. As men become older, it is more likely that their adult children move away and form independent households, but they are also more likely to have grandchildren. Men are more likely to be living with either children or grandchildren if they are married or have some formal education. The education result is particularly interesting because it differs from results found in some other parts of the world (DaVanzo and Chan 1994; Martin 1989) and does not conform to modernization theory. These differences are likely a result of cultural norms in Africa, where better-off family members are required by tradition to support other family members, and this may include coresidency. The effects of rural residence are mixed. For instance, urban men are more likely to live with an adult child, while rural men are more likely to live with a grandchild but no adult child.

For women, individual characteristics are not as strongly associated with living arrangements, with the exception of the probability of living with grandchildren but no adult children. Women over age 75 are less likely to live in this situation, while women living in rural areas and with some formal education are more likely to do so. The positive effect of rural residence for both men and women when it comes to living with a grandchild and no adult child may reflect substantial migration of adult children from rural to urban areas, with grandchildren left behind with grandparents. This may particularly be the case in the de jour measurement of household membership, where semipermanent members are more likely to be coded as living elsewhere.

A notable difference in effects by sex is that, for men, living with children and grandchildren appears to be tied with living with a spouse, but for women the effect is either not significant or in the opposite direction. Clearly, women without a spouse are more dependent and may need to rely on extended family, thus they tend to live with grandchildren more often. Women may also be more helpful in the household, whereas men may rely on their spouse for domestic care. Men also are more likely to control resources and thus able to demand coresidence as a form of support. Nevertheless, the precise reasons for these associations are speculative since our data do not allow us to test for causal connections. 
Our results thus far suggest that older adults in sub-Saharan Africa are found in a multitude of living arrangements with a variety of household members. Many older adults live in complex arrangements with extended family. Men are more likely to live with children, while women are more likely to live in other situations, including with grandchildren and alone. Our results do not support a modernization argument and they differ from results found in other parts of the world, particularly with respect to the effect of education, which in our DHS sample tends to increase the likelihood of coresidence. The elderly in rural areas are more likely to live with grandchildren but no children, and this indicates a higher degree of fostering-in rather than the influence of modernization.

\section{Living with children and grandchildren according to level of HIV/AIDS}

We now examine how the distributions of living with children and grandchildren differ across countries with higher and lower levels of HIV/AIDS. The 16 countries in our study fall into three distinct HIV/AIDS categories based on the number of HIV/ AIDS-related deaths per 1,000 population measured in 1997. We call the three groups low, high, and very high. The seven low HIV/AIDS countries had 1.3 or fewer deaths per 1,000 in 1997. The six countries defined as having high rates had between 3.8 and 4.9 deaths. Finally, three countries fall into the very high category: Uganda (7.7), Zambia (11.4), and Zimbabwe (11.7). Individuals living within each of the three groups are pooled, and results refer to all individuals within the grouping.

Table 6 indicates the percent of older adults living with adult children, grandchildren under 15, and with grandchildren but no children, across these three country groupings. The tendency to live with an adult child is highest in countries with low levels of AIDS mortality. In contrast, living with a grandchild is most common in countries with very high levels of AIDS mortality. The proportion living with grandchildren under 15 but no adult children in the household is almost twice as high in countries with very high levels of HIV/AIDS (21 percent) as in countries with low or high levels. The differences across the three country groupings are all statistically significant. ${ }^{6}$

Table 7 allows us to examine a possible connection between HIV/AIDS and coresidence with grandchildren. The table presents the results according to whether the 
Table 6 Percent of older adults living in specific arrangements by level of HIV/AIDS

\begin{tabular}{lccc}
\hline Living arrangement & Low HIV/AIDS $^{\text {a }}$ & High HIV/AIDS $^{\text {a }}$ & $\begin{array}{c}\text { Very high } \\
\text { HIV/AIDS }^{\text {a }}\end{array}$ \\
\hline $\begin{array}{l}\text { Lives with an adult child } \\
\text { Lives with a grandchild under 15 }\end{array}$ & 54.8 & 50.4 & 43.4 \\
$\begin{array}{l}\text { Lives with a grandchild under 15 } \\
\text { but no adult children in the household }\end{array}$ & 36.2 & 42.4 & 48.8 \\
\hline
\end{tabular}

Note: Comparisons across levels of HIV/AIDS significant at $\mathrm{p}<.05$ in all cases.

a HIV/AIDS Low (HIV/AIDS-related mortality rates of 1.3 per 1,000 or less): Madagascar, Benin, Ghana, Guinea, Mali, Niger, Nigeria; High (HIV/AIDS-related mortality rates between 3.8 and 4.9 per 1,000): Burkina Faso,

Ethiopia, Kenya, Mozambique, Tanzania, Togo; Very high (HIV/AIDS-related mortality rates of 7.7 per 1,000 or higher): Uganda, Zambia, Zimbabwe.

parents of grandchildren who live with older adults are present in the household. If a parent is absent, the table also shows the possible reasons for the absence. (This table does not include any data from Burkina Faso because the question on survival was not included in that country's DHS.) These situations are examined for countries grouped into low, high, and very high levels of HIV/AIDS. There is also a total column that combines the data from the 15 countries (i.e., the original 16 countries minus Burkina Faso). The absence of a parent of a grandchild could be due to one of two reasons. The parent may be living away from the household, or he or she may have died, possibly from AIDS. In our DHS data the whereabouts of the grandchild's parents are unknown, thus they may be either alive or dead.

The upper panel of Table 7 shows the results for all older adults, and the lower panel shows the results for older adults who live with grandchildren under the age of 15 . In the upper panel we see that 11 percent of all older adults in sub-Saharan Africa live in a household with a grandchild and both of the grandchild's parents. In the lower panel we see that of older adults who live with grandchildren, 27 percent live with a grandchild and both of the grandchild's parents. Since overall about 40 percent of older adults live with grandchildren (see Table 4), the figure in the upper panel will be about 40 percent of the figure in the lower panel. We should note that an older adult might live in more than one of these arrangements, and the results here are therefore not mutually exclusive. For instance, an older adult may live with one grandchild whose parents are both present as well as with another grandchild whose parents are both absent. It is also possible that there may be several grandchildren in the household whose parents are both absent. 
Table 7 Percent of older adults who live with grandchildren, according to presence or absence of parents and coresidence of the grandchildren's parents, by level of HIV/AIDS

\begin{tabular}{|c|c|c|c|c|}
\hline & Total & $\begin{array}{c}\text { Low } \\
\text { HIV/AIDS }^{a}\end{array}$ & $\begin{array}{c}\text { High } \\
\text { HIV/AIDS }\end{array}$ & $\begin{array}{l}\text { Very high } \\
\text { HIV/AIDS }^{\mathrm{a}}\end{array}$ \\
\hline \multicolumn{5}{|l|}{ Among all older adults } \\
\hline \multicolumn{5}{|l|}{ Presence of parents } \\
\hline Both parents present & 10.6 & 11.4 & 10.4 & 7.2 \\
\hline One parent present & 12.4 & 10.3 & 13.9 & 16.5 \\
\hline Both parents absent & 22.5 & 18.9 & 24.4 & 34.1 \\
\hline \multicolumn{5}{|c|}{ Reasons for parents being absent } \\
\hline \multicolumn{5}{|c|}{ At least one parent alive but not } \\
\hline living in the household & 27.9 & 23.1 & 31.6 & 39.7 \\
\hline At least one parent dead & 7.9 & 5.1 & 9.2 & 17.8 \\
\hline $\begin{array}{l}\text { At least one parent with } \mathrm{u} \\
\text { survival status }\end{array}$ & 2.7 & 3.0 & 2.1 & 3.8 \\
\hline \multicolumn{5}{|c|}{$\begin{array}{l}\text { Among older adults living with } \\
\text { a grandchild }\end{array}$} \\
\hline \multicolumn{5}{|l|}{ Presence of parents } \\
\hline Both parents present & 27.1 & 32.0 & 24.8 & 14.8 \\
\hline One parent present & 31.0 & 28.5 & 32.8 & 33.8 \\
\hline Both parents absent & 57.1 & 53.0 & 58.1 & 70.0 \\
\hline \multicolumn{5}{|c|}{ Reasons for parents being absent } \\
\hline living in the household & 71.1 & 65.0 & 75.1 & 81.6 \\
\hline At least one parent dead & 20.0 & 14.3 & 21.9 & 36.6 \\
\hline $\begin{array}{l}\text { At least one parent with un } \\
\text { survival status }\end{array}$ & 6.8 & 8.3 & 4.9 & 7.9 \\
\hline
\end{tabular}

Note: Comparisons across levels of HIV/AIDS significant at $\mathrm{p}<.05$ in all cases.

a For definition see note a to Table 6.

Table 7 also indicates that it is common for older adults in sub-Saharan Africa to live with grandchildren one or both of whose parents are absent. Looking at the first column, which shows results for all countries, 23 percent of older adults in sub-Saharan Africa live with a grandchild whose parents are both absent from the household. Of all older adults living with grandchildren, the total is $\mathbf{5 7}$ percent. It is more common for older adults to live with a grandchild whose parents are both absent than it is to live with a grandchild whose parents are present. This statistic alone provides evidence of the importance of grandparenting across sub-Saharan Africa. 
The most common reason for parents to be absent is that they are living elsewhere. Specifically, of all older adults, 28 percent live with a grandchild who has at least one parent living elsewhere. But mortality also explains some instances of parental absence from the households of older adults. About 8 percent of all older adults live with a grandchild who has a deceased parent; among older adults living with grandchildren, this figure is 20 percent. An additional 3 percent of all older adults live with a grandchild who has at least one parent with an unknown status.

The other three columns in Table 7 show the results by level of HIV/AIDS, as defined in Table 6. Older adults living in countries with very high levels of HIV/AIDS most often live in situations where there are grandchildren without parents. Specifically, 34 percent of older adults in countries with very high levels of HIV/AIDS, 24 percent in countries with high levels, and 19 percent in countries with low levels live with a grandchild with both parents absent. The absence of the parent is explained both by their living elsewhere and by mortality across all three HIV/AIDS levels, but looking at the highest level is informative for suggesting the influence of mortality on coresidence with grandparents. Nearly 40 percent of all older adults in countries with very high HIV/ AIDS levels live with at least one grandchild in the household who has at least one parent living elsewhere. However, some 18 percent of older adults in these countries live with at least one grandchild in the household who has at least one deceased parent. By contrast, in low HIV/AIDS countries about 23 percent live in a household with a grandchild who has a parent living elsewhere, and only 5 percent of older adults live with a grandchild who has a deceased parent. ${ }^{7}$

\section{Living with double-orphans}

The results shown in Table 7 confirm, first, that in countries with high HIV/AIDS rates the grandchildren who live with older adults are quite likely to have parents living elsewhere, and second, that the absence of a parent can also be explained, to a lesser extent, by mortality. Although we might assume that the association between HIV/AIDS rates and the absence of a grandchild's parent or parents is explained by an AIDS-related death, this is still only an indirect speculation. One way of focusing more closely on the potential association with AIDS mortality is by looking at double-orphans, that is, grand- 
children whose parents are both deceased. Where the spread of HIV is mainly through heterosexual contact, as in sub-Saharan Africa, we would expect that the death of both parents is the result of AIDS due to the transmission of the HIV virus between the couple. Therefore, we can expect that the probability of living with a double-orphan is higher for older adults in countries with high rates of HIV/AIDS.

For greater specificity, we change our analytical strategy here from looking at aggregate data to looking at data within individual countries. Figure 1 shows the number of double-orphans per 1,000 population within countries, determined using DHS data on parental survival, according to the country-level HIV/AIDS-related crude death rates reported in Table 1. Because survival data are obtained in the DHS only for parents of children under age 15, double-orphans are defined as children under 15 with both parents deceased. The unweighted average number of double-orphans per 1,000 population is 4.2. However, the number varies according to the HIV/AIDS-related mortality rate, and there is a strong linear association. For instance, most of the low HIV/AIDS countries have two or fewer double-orphans per 1,000 population, while Uganda and Zimbabwe, two

Figure 1 Number of double-orphans per 1,000 population by HIV/AIDS-related mortality rate

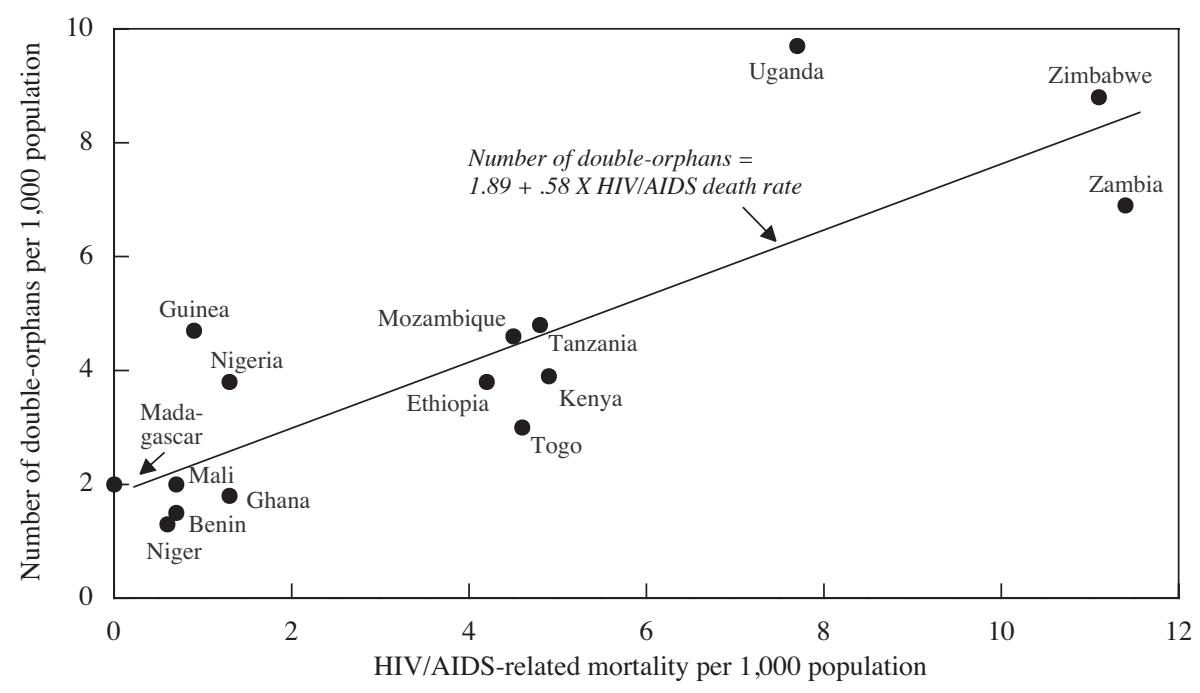


of the highest HIV/AIDS countries in the world, have about nine or ten. Also shown in Figure 1 is the regression equation for the association, which suggests that an increase of one HIV/AID-related death will add a little more than one-half of a double-orphan to the population.

While HIV/AIDS-related mortality is associated with the number of double-orphans in a country, Figure 2 shows that it is also associated strongly with the share of older adults who live with a double-orphan. In 15 countries of sub-Saharan Africa (excluding Burkina Faso), 1.7 percent of older adults live with at least one double-orphaned grandchild. (About 4 percent of those living with grandchildren live with at least one doubleorphaned grandchild across the entire region.) However, nearly 5 percent of all older adults in Zimbabwe and Uganda live in a household with at least one double-orphan present. The share living with a double-orphan is also high in Zambia and Tanzania, two other countries with high HIV/AIDS-related mortality rates. The regression equation shows that a oneunit increase in the HIV/AIDS death rate corresponds to an increase in the percent of older adults living with a double-orphan of more than one-quarter.

Figure 2 Percent of older adults living with a double-orphaned grandchild by HIV/AIDS-related mortality rate

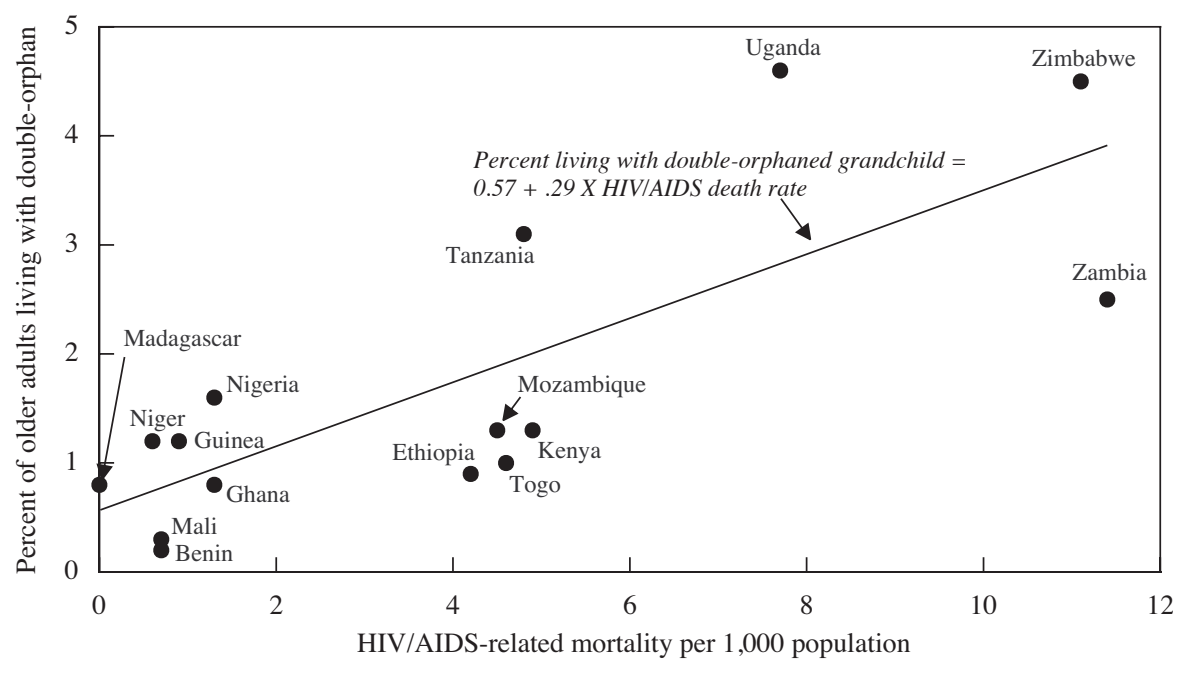


Further analysis that we conducted but have not shown in tabular form indicates that about one-third of households with double-orphans have two double-orphans, but rarely are there more than two. In the three countries with very high HIV/AIDS-related mortality rates, about half of the households with double-orphans have more than one double-orphan present. These additional statistics suggest that those older adults who care for orphans are often likely to be caring for more than one at a time.

Some of the variation around the regression lines seen in Figures 1 and 2 may be a result of using HIV/AIDS-related mortality rates from one year (1997) rather than cumulative death rates (which are unavailable to us). For instance, the percent of older adults living with double-orphans in Uganda comes from the 1995 DHS survey. There may have been more double-orphans in Uganda in 1995 than would be predicted by the 1997 death rate if HIV/AIDS-related deaths were on the decline in Uganda. Similarly, because the Nigeria DHS was conducted after 1997, the overestimate of the number of double-orphans there could be the result of rising rates of HIV/AIDS-related mortality. Nevertheless, the regression lines from both figures represent a strong relationship and one that is highly correlated (Pearson's $r$ of .85 and .77 respectively.)

\section{DISCUSSION}

The growth in the number and proportion of older adults in sub-Saharan Africa coupled with an AIDS epidemic that adversely affects their welfare necessitates that more attention be paid to this segment of the region's population. In our study we found that older adults in the region are fairly likely to live in either nuclear or extended household arrangements. Men are more likely to be living in the former, and women in the latter. Although we were unable to investigate the reasons for these sex differences in detail, we suspect that women are more likely to be dependent on family support and to assume important household tasks, including child care. In total, 61 percent of older adults in sub-Saharan Africa live with a child and 43 percent live with a grandchild. On the basis of the sex of children-in-law living with older adults, we saw evidence of the

preference for living with sons in coresidence arrangements. We examined some basic determinants of these arrangements and found differences by sex, difference from what 
has been seen in other parts of the world, particularly with respect to education of parents, and little support for the modernization perspective.

During the United Nations Second World Assembly on Ageing, held in Madrid in April 2002, much attention was directed to the potential of the HIV/AIDS pandemic for burdening older adults with care responsibilities. "At a time when it is more normal for adult children to look after their ageing parents, many older persons find themselves with the unexpected responsibility of caring for frail children or with the task of becoming sole parents to grandchildren" (United Nations 2002: 35). In the current study, we indeed found that older adults frequently live with grandchildren one or both of whose parents are absent. Some 13 percent of older adults in sub-Saharan Africa live with at least one grandchild but with none of their own adult children also in the household. We found that this tendency occurs with greater regularity in countries with high AIDS-related mortality. However, we also found that this situation, which implies a fostering arrangement, would exist with or without the AIDS epidemic, as a majority of the absent parents are alive but live elsewhere. This is a more common situation in rural areas, perhaps indicating that the parent has left to find work elsewhere. Nonetheless, we also found strong associations between AIDS-related mortality and the tendency for the elderly to live with grandchildren whose parents are deceased. About 18 percent of older adults in the three countries with very high AIDS mortalities (Uganda, Zimbabwe, and Zambia) live in a household containing an orphaned grandchild. An additional several percent live with grandchildren whose parents' whereabouts are unknown, indicating that they too may be deceased. We showed, too, that HIV/AIDS-related mortality rates are strongly associated with the share of older adults living with double-orphaned grandchildren.

The results suggest a complex set of associations between fostering as normative behavior within sub-Saharan African culture, rates of HIV/AIDS, and living arrangement patterns. For instance, where fostering is culturally accepted, adults are likely to leave their children with grandparents. They then migrate for work, and at the same time they may adopt sexual practices away from home that increase their likelihood of contracting HIV. This leads to higher AIDS-related mortality rates and in turn alters the availability of children and the long-term needs of grandchildren. But the current study, given its cross-sectional nature, cannot fully establish these causal connections, and we 
caution that many confounding factors are likely involved. An example is level of education, which tends to be higher in countries with higher rates of HIV infection. Crosscountry analysis showed coresidence with children to be lower in countries with higher levels of education (Bongaarts and Zimmer 2002). One reason for this is that employment opportunities that come with higher education tend to take people away from their place of birth. Higher education may be related to more liberal sexual practices, and perhaps migration itself is associated with sexual practices that put an individual at risk for HIV infection.

Although we believe it is likely that the AIDS epidemic is changing living arrangement patterns and the needs of older adults, the magnitude of these changes is also important to consider. The regression equations in Figures 1 and 2 suggested that a sharp rise in the epidemic across the region could increase the number of double-orphans by about 3 per 1,000 population and the proportion of older adults living with double-orphans by 1 to 2 percent. Given an expected population size for East and West sub-Saharan Africa combined of about 700 million by the year 2020 (United Nations 2001), the former estimate represents a rise in the number of double-orphans on the order of 2 million. With an expected population of older adults in the region reaching 38 million by the year 2020 (United Nations 2001), the latter estimate could represent several hundred thousand additional older adults living with a double-orphaned grandchild. These numbers will, of course, be dependent upon many other factors not accounted for in the current study, but they provide some indication of the magnitude of the problem.

Other circumstances, such as living in poverty and the migration of adult children from rural to urban areas, may affect the well-being and living arrangements of the older population to an even greater degree. At the same time, Africa's limited resources and the many competing needs of older adults necessitate the identification of those most critical for their survival and welfare. Awareness of the types of households in which older people live is a first step to understanding these needs. The results we provide here may be seen as a baseline from which to gauge the region as it undergoes change. Perhaps more importantly, there is a need to confirm, explain and ultimately expand on our findings. We identify three areas that would be especially useful. First, as more time passes and longitudinal data become available, it will be essential to assess how changes 
in AIDS-related mortality are associated with changes in living arrangements. As yet, adequate data are unavailable. For instance, for those countries in our study that have had more than one DHS survey, the time lapse between the two is too short-usually no longer than five or six years - and the number of countries that have had more than one survey is too small. ${ }^{8}$ Further, AIDS-related mortality rates are not readily available for years before 1997. Second, an analysis that examines support mechanisms in more detail, and how AIDS-related mortality influences these, is needed. This will require detailed survey data that are representative of the population and contain information about individual, household, and community-level factors associated with living arrangements, intergenerational relations, and sources of formal and informal support. Finally, work is needed to expand the analysis beyond living arrangements to other measures of the wellbeing of the elderly. Such research can help to identify policies to mitigate the adverse effects of the AIDS epidemic and of other factors that unfavorably affect the lives of older adults in the region.

\section{NOTES}

The authors thank John Bongaarts for his comments on an earlier version of this paper. An earlier version was presented at the Annual Meeting of the Gerontological Association of America, Boston, November 25, 2002.

1 BMI of persons older than age 50 declined in better-off households prior to an adult death and in households not receiving private assistance shortly after an adult death. However, BMI eventually recovered.

2 Such reconstruction is computationally time consuming and involves an intricate set of recodes; but in most cases the relationships are easily determined because the older adult is listed as head, spouse of head, or parent or parent-in-law of head. As such, determining whether an older adult lives with children and grandchildren is not difficult. Identifying other precise relationships, for instance aunts and uncles, may be more complex, but this information is not required for the current study. 
3 We selected 1997 because it is the year closest to our survey years for which AIDS mortality data are available.

4 The DHS data are provided with individual weights that make cases representative of the national population. Since our focus is on region rather than country, we created an additional weight for each country that resulted in the number of cases being proportional to the number aged 60 and older living in the country at the time the DHS was conducted. This makes the data representative of the region, but it also gives high weight to countries with large populations (e.g., Nigeria) and low weight to countries with small populations (e.g., Togo). This is most suitable for our purpose, namely, to determine living arrangements generalized on the regional level; but an alternate weighting procedure, which would put more emphasis on country-specific results, gives equal weight to each individual in the pooled sample, a technique that makes each country equally important. All the procedures listed below were conducted using this alternate weighting procedure as well. The results are not shown because of space limitations, but they are available from the authors upon request.

5 The country effects are not shown owing to spatial limitations but may be requested from the authors.

6 In further analysis, not reported here but available from the authors upon request, these proportions were examined separately for men and women. The patterns are similar across the three levels of HIV/AIDS, although, as seen earlier, proportions living with adult child are higher for men, while proportions living with grandchildren and grandchildren without adult children are higher for women.

7 Further analysis, not shown in tabular form, indicates that the deceased parent is slightly more likely to be the father than the mother. For instance, among all older adults in sub-Saharan Africa, 4.2 percent live in a household with a grandchild whose mother is deceased, while 5.9 percent live in a household with a grandchild whose father is deceased. These further analyses are available from the authors upon request. 
8 Longitudinal analyses based on available data over time were conducted for this study, but results were found to be inconclusive with respect to change and invalid owing to short time intervals between surveys.

\section{REFERENCES}

Adamchak, Donald J., Adrian O. Wilson, Andrew Nyanguru, and Joseph Hampson. 1991. "Elderly support and intergenerational transfer in Zimbabwe: An analysis by gender, marital status, and place of residence," The Gerontologist 31(4): 505-513.

Ainsworth, Martha and Julia Dayton. 2003. "The impact of the AIDS epidemic on the health of older persons in northwestern Tanzania," World Development 31(1): 131-148.

Albert, Stephen M. and Maria G. Cattell. 1994. "Family relationships of the elderly: Living arrangements," in Old Age in Global Perspective: Cross-Cultural and Cross-National Views, pp. 85-107. New York: G.K. Hall \& Co.

Andrews, Gary R., A.J. Esterman, A.J. Braunack-Mayer, and C.M. Rungie. 1986. Aging in the Western Pacific: A Four Country Study. Manila, Philippines: World Health Organization.

Anh, Truong Si, Bui The Cuong, Daniel Goodkind, and John Knodel. 1997. "Living arrangements, partilineality and sources of support among elderly Vietnamese," Asia-Pacific Population Journal 12(4): 69-88.

Apt, Nana Araba. 1992. "Family support to elderly people in Ghana," in Hal L. Kendig, Akiko Hashimoto, and Larry C. Coppard (eds.), Family Support for the Elderly: The International Experience, pp. 203-212. New York: Oxford University Press.

Asis, Maruja Milagros B., Lita Domingo, John Knodel, and Kalyani Mehta. 1995. "Living arrangements in four Asian countries: A comparative perspective," Journal of Cross-Cultural Gerontology 10: 145-162.

Ayad, Mohamed, Bernard Barrere, and Jeames Otto. 1997. "Demographic and socioeconomic characteristics of households," DHS Comparative Studies No. 26. Calverton, MD: Macro International Inc. 
Aykan, Hakan and Douglas A. Wolf. 2000. "Traditionality, modernity, and household composition: Parent-child coresidence in contemporary Turkey," Research on Aging 22(4): 395-421.

Barnett, T. and P. Blaikie. 1992. AIDS in Africa: Its Present and Future Impact. London: Belhaven Press.

Bicego, George, Shea Rutstein, and Kiersten Johnson. 2001. "Dimensions of the emerging orphan crisis in sub-Saharan Africa," paper presented at the Annual Meeting of the Population Association of America, Washington, DC.

Bongaarts, John and Zachary Zimmer. 2002. "Living arrangements of the elderly in the developing world: An analysis of DHS household surveys," Journal of Gerontology: Social Sciences 57(1): S145-S157.

Cameron, Lisa. 2000. "The residency decision of elderly Indonesians: A nested logit analysis," Demography 37(1): 17-27.

Case, Anne, Christina Paxson, and Joseph Ableidinger. 2002. “Orphans in Africa," National Bureau of Economic Research Working Paper Series \#9213. Cambridge, MA.

Casterline, John B., Lindy Williams, Albert Hermalin, M.C. Chang, Napaporn Chayovan, Paul Cheung, Lita Domingo, John Knodel, and Mary Beth Ofstedal. 1991. "Differences in the living arrangements of the elderly in four Asian countries: The interplay of constraints and preferences," Comparative Study of the Elderly in Asia Research Reports, No. 91-10. Ann Arbor: Population Studies Center, University of Michigan.

Cattell, Maria G. 1990. "Models of old age among the Samia of Kenya: Family support of the elderly," Journal of Cross-Cultural Gerontology 5: 375-394.

Chan, Angelique. 1997. "An overview of the living arrangements and social support exchanges of older Singaporeans," Asia-Pacific Population Journal 12(4): 35-50.

Cowgill, Donald O. 1986. Aging Around the World. Belmont, CA: Wadsworth.

DaVanzo, Julie and Angelique Chan. 1994. "Living arrangements of older Malaysians: Who co-resides with their adult children?," Demography 31(1): 95-113.

DeVos, Susan. 1990. "Extended family living among older people in six Latin American countries," Journal of Gerontology: Social Sciences 45(3): 87-94. 
DeVos, Susan. 1998. "Regional differences in living arrangements among the elderly in Ecuador," Journal of Cross-Cultural Gerontology 13: 1-20.

Goode, William J. 1963. World Revolution and Family Patterns. Glencoe, IL: Free Press. Hermalin, Albert I. 1993. "Fertility and family planning among the elderly in Taiwan or integrating the demography of aging into population studies," Demography 30(4): 507-517.

Hermalin, Albert I. 1995. "Aging in Asia: Setting the research foundation.” Asia-Pacific Population Research Reports, No. 4. Honolulu: East-West Center.

Hoddinott, John. 1993. "Family size and support to the elderly in western Kenya," in Fertility, Family Size, and Structure: Consequences for Families and Children. New York: Population Council.

Hunter, S and J. Williamson. 1998. "Responding to the needs of children orphaned by HIV/AIDS.” TvT Associates, Health Technical Services Project, Discussion Paper on HIV/AIDS Care and Support No. 7. Arlington, VA.

Knodel, John and Napaporn Chayovan. 1997. "Family support and living arrangements of Thai elderly," Asia-Pacific Population Journal 12(4): 1-17.

Knodel, John and Nibhon Debavalya. 1997. "Living arrangements and support among the elderly in South-East Asia: An introduction," Asia-Pacific Population Journal 12(4): 5-16.

Knodel, John, Chanpen Saengtienchai, Wassana Im-em, and Mark VanLandingham. 2001. "The impact of AIDS on parents and families in Thailand: A key informant approach," Research on Aging 23(6): 633-670.

Knodel, John, Mark VanLandingham, Chanpen Saengtienchai, and Wassana Im-em. 2001. "Older people and AIDS: Quantitative evidence of the impact in Thailand," Social Science and Medicine 52(9): 1313-1327.

Levy, Marion J. 1966. Modernization and the Structure of Societies. Princeton, NJ: Princeton University Press.

Lloyd, Cynthia B. and Sonalde Desai. 1992. "Children's living arrangements in developing countries," Population Research and Policy Review 11: 193-216. 
Logan, John R., Fuqin Bian, and Yanjie Bian. 1998. "Tradition and change in the urban Chinese family: The case of living arrangements," Social Forces 76(3): 851-882.

Martin, Linda G. 1989. "Living arrangements of the elderly in Fiji, Korea, Malaysia, and the Philippines," Demography 26(4): 627-643.

Martin, Linda G. and Kevin Kinsella. 1994. "Research on the demography of aging in developing countries," in Linda G. Martin and Samuel H. Preston (eds.), Demography of Aging, pp. 356-403. Washington, DC: National Academy Press.

Mason, Karen Oppenheim. 1992. "Family change and support of the elderly in Asia: What do we know?," Asia-Pacific Population Journal 7:13-32.

Merli, M. Giovanna and Alberto Palloni. 2001. "The HIV/AIDS epidemic, kin relations, living arrangements and the elderly in South Africa," paper presented at the IUSSP General Conference in Salvador, Brazil.

National Research Council. 1996. Preventing and Mitigating AIDS in Sub-Saharan Africa: Research and Data Priorities for the Social and Behavioral Sciences. Washington, DC: National Academy Press.

Natividad, Josefina N. and Grace T. Cruz. 1997. "Patterns in living arrangements and familial support for the elderly in the Philippines," Asia-Pacific Population Journal 12(4): 17-34.

Ntozi, James P.M. and Sylvia Nakayiwa. 1999. "AIDS in Uganda: How has the household coped with the epidemic?," in I.O. Orubuloye, J. C. Caldwell, and J. P. M. Ntozi (eds.), The Continuing HIV/AIDS Epidemic in Africa: Responses and Coping Strategies, pp. 155-181. Canberra: Australian National University.

Nydegger, Corinne N. 1983. "Family ties of the aged in cross-cultural perspective," The Gerontologist 23(1): 26-32.

Palloni, Alberto, Susan DeVos, and M. Pelaez. 1999. “Aging in Latin America and the Caribbean.” Working Paper No. 99-02. Madison, WI: University of WisconsinMadison, Center for Demography and Ecology.

Palloni, Alberto. 2000. "Living arrangements of older persons," in Population Division of the Department of Economic and Social Affairs (ed.), United Nations Techni- 
cal Meeting on Population Ageing and Living Arrangements of Older Persons: Critical Issues and Policy Responses, pp. 2-1-2-45. New York: United Nations.

Peil, Margaret. 1985. "Old age in West Africa: Social support and quality of life," in John H. Morgan (ed.), Aging in Developing Societies: A Reader in Third World Gerontology, pp. 1-21. Bristol, IN: Wyndham Hall Press.

Rajan, S. Irudaya, U.S. Mishra, and P.S. Sarma. 1995. "Living arrangements among the Indian elderly," Hong Kong Journal of Gerontology 9(2): 20-28.

Thomas, Samuel P. 1995. "Shifting meanings of time, productivity and social worth in the life course in Meru, Kenya," Journal of Cross-Cultural Gerontology 10(3): 233-256.

UNAIDS. 1997. "Table of country-specific HIV/AIDS estimates and data, end 1997." New York: United Nations.

United Nations. 2002. Report of the Second World Assembly on Ageing. New York: United Nations.

United Nations. 2001. World Population Prospects: The 2000 Revision. New York: United Nations.

VanLandingham, Mark, John Knodel, Wassana Im-em, and Chanpen Saengtienchai. 2000. "The impact of HIV/AIDS on older populations in developing countries: Some observations based upon the Thai case," Population Studies Center, University of Michigan, Research Report Series.” Ann Arbor, MI.

World Bank. 1999. Confronting AIDS: Public Priorities in a Global Epidemic, Revised Edition. New York: Oxford University Press.

World Bank. 2000. Intensifying Action Against HIV/AIDS in Africa. Washington, DC: World Bank.

World Health Organization. 2002. Impact of AIDS on Older People in Africa: Zimbabwe Case Study. Geneva: World Health Organization.

Zimmer, Zachary and Sovan Kiry Kim. 2001. "Living arrangements and sociodemographic conditions of older adults in Cambodia," Journal of Cross-Cultural Gerontology 16(4): 353-381. 


\title{
POLICY RESEARCH DIVISION WORKING PAPERS
}

\author{
Recent Back Issues
}

144 John Bongaarts, "Household size and composition in the developing world."

145 John B. Casterline, Zeba A. Sathar, and Minhaj ul Haque, "Obstacles to contraceptive use in Pakistan: A study in Punjab."

146 Zachary Zimmer, Albert I. Hermalin, and Hui-Sheng Lin, "Whose education counts? The impact of grown children's education on the physical functioning of their parents in Taiwan."

147 Philomena Nyarko, Brian Pence, and Cornelius Debpuur, "Immunization status and child survival in rural Ghana."

*148 John Bongaarts and Zachary Zimmer, "Living arrangements of older adults in the developing world: An analysis of DHS household surveys."

149 Markos Ezra, "Ecological degradation, rural poverty, and migration in Ethiopia: A contextual analysis."
150 Cynthia B. Lloyd, Sahar El Tawila, Wesley H. Clark, and Barbara S. Mensch, "Determinants of educational attainment among adolescents in Egypt: Does school quality make a difference?"

151 Barbara S. Mensch, Paul C. Hewett, and Annabel Erulkar, "The reporting of sensitive behavior among adolescents: A methodological experiment in Kenya."

152 John Bongaarts, "The end of the fertility transition in the developed world."

153 Mark R. Montgomery, GebreEgziabher Kiros, Dominic Agyeman, John B. Casterline, Peter Aglobitse, and Paul Hewett, "Social networks and contraceptive dynamics in southern Ghana."

*154 Paul C. Hewett and Mark R. Montgomery, "Poverty and public services in developing-country cities."

* No longer available 
155 Zachary Zimmer, Linda G. Martin, and Ming-Cheng Chang, "Changes in functional limitations and survival among the elderly in Taiwan: 1993, 1996, and 1999."

156 John Bongaarts and Griffith Feeney, "How long do we live?"

157 Zachary Zimmer and Sovan Kiry Kim, "Living arrangements and socio-demographic conditions of older adults in Cambodia."

158 Geoffrey McNicoll, "Demographic factors in East Asian regional integration."

159 Carol E. Kaufman, Shelley Clark, Ntsiki Manzini, and Julian May, "How community structures of time and opportunity shape adolescent sexual behavior in South Africa."

160 Julia Dayton and Martha Ainsworth, "The elderly and AIDS: Coping strategies and health consequences in rural Tanzania."

161 John Bongaarts, "The end of the fertility transition in the developing world."
162 Naomi Rutenberg, Carol E. Kaufman, Kate Macintyre, Lisanne Brown, and Ali Karim, "Pregnant or positive: Adolescent childbearing and HIV risk in South Africa."

163 Barbara S. Mensch, Wesley H. Clark, and Dang Nguyen Anh, "Premarital sex in Vietnam: Is the current concern with adolescent reproductive health warranted?"

164 Cynthia B. Lloyd, Cem Mete, and Zeba A. Sathar, "The effect of gender differences in primary school access, type, and quality on the decision to enroll in rural Pakistan."

165 Kelly Hallman, Agnes R. Quisumbing, Marie Ruel, and Bénédicte de la Brière, "Childcare, mothers' work, and earnings: Findings from the urban slums of Guatemala City."

166 Carol E. Kaufman and Stavros E. Stavrou, "'Bus fare, please': The economics of sex and gifts among adolescents in urban South Africa."

167 Dominic K. Agyeman and John B. Casterline, "Social organization and reproductive behavior in southern Ghana." 
168 Paul C. Hewett, Annabel S. Erulkar, and Barbara S. Mensch, "The feasibility of computer-assisted survey interviewing in Africa: Experience from two rural districts in Kenya."

169 Zachary Zimmer and Julia Dayton, "The living arrangements of older adults in sub-Saharan Africa in a time of HIV/AIDS." 